\title{
SURDEZ, MEDIAÇÃO E LINGUAGEM NA ESCOLA'
}

\section{Rute Oliveira do Bomfim}

Ana Paula Ramos de Souza

Resumo: Este estudo examina como os princípios de mediação, tomando por base a Experiência de Aprendizagem Mediada (EAM), de Reuven Feuerstein, e de aquisição da linguagem numa abordagem interacionista, podem interferir nas práticas educacionais e/ ou terapêuticas na surdez, considerando a linguagem com foco de aprendizagem/aquisição. $O$ contexto de pesquisa foi um grupo de quatro crianças surdas e suas duas professoras, uma surda falante de LIBRAS (Língua Brasileira de Sinais) e outra ouvinte responsável pelo português.O objetivo foi analisar o quão frequentes foram os princípios de mediação e de aquisição antes e depois de uma intervenção formativa com as professoras. Também se investigaram as consequências na linguagem das crianças em ambas as línguas e no contexto familiar. Os resultados demonstraram consequências importantes na comunicação das crianças, observadas pelas mães no contexto familiar, e mudanças no processo de mediação das professoras em sala de aula. Entre os princípios mais frequentes encontraram-se os de intencionalidade-reciprocidade, busca de significado, transcendência e mediação do sentimento de competência. As crianças se tornaram mais ativas tanto na sala de aula quanto no contexto familiar.

Palavras-chave: Mediação. Aprendizagem. Linguagem. Interação. Surdez.

\section{A Educação de Surdos}

Tradicionalmente, a educação de surdos tem como centro das investigações o resultado de testes formais e debates sobre métodos da comunicação, perdendo de

1 Este trabalho é uma síntese da dissertação de mestrado da primeira autora, orientada pela segunda autora, cujo título foi: Concepções de linguagem e educação e a defesa da Experiência de Aprendizagem Mediada como parâmetro de interação entre um grupo de crianças surdas e suas professoras. 
vista o processo de aquisição da linguagem como um processo de constituição de sujeitos, futuros cidadãos. O papel das interações iniciais, sejam elas escolares ou familiares, não é devidamente valorizado (Wood, 1992), e a linguagem é tomada como fruto de um código a ser dominado: a língua. Assim, domina a visão comportamentalista (Góes, 1999; Goldfeld, 1997; Souza, 1998; Trenche, 1995), na qual o surdo é submetido a um treinamento, o que não permite transcender a "patologia". A consequência de tal situação educacional pode ser sentida no depoimento de adultos surdos que relatam sua exclusão social manifesta no não acesso ao trabalho, à vida relacional, ao lazer, enfim, à cidadania (Borne, 2002).

A superação de tal modelo, iniciada pela concepção inatista que trata a linguagem na surdez como uma questão de bilinguismo, é maior nas concepções sócio-históricas, introduzidas por autores como Bakhtin (1997) e desenvolvidas por Vygotsky (1991) na Psicologia. O primeiro autor coloca a língua/linguagem num plano histórico e dinâmico, no qual os sujeitos são constituídos por ela ao mesmo tempo em que a constituem, e formula um dos princípios mais importantes no processo de aquisição da linguagem: a necessidade de inserção da língua em rotinas significativas, cujo lócus inicial é a família e, depois, a escola. A clínica e a escola exercerão, no caso da surdez, o papel de mediador entre o surdo e sua família ouvinte, e do surdo com a sociedade, porque não só vão minimizar os efeitos da doença (a surdez), mas também devem ser espaços de promoção da saúde e da qualidade de vida. $O$ fracasso na atuação desses dois campos pode ser indutor de um processo de exclusão social do surdo, pois sem dominar ao menos uma língua, ele pode ter acesso dificultado a boas condições de trabalho, à educação, à cultura física e a formas de lazer e descanso, enfim, à democracia e cidadania, aspectos inerentes à saúde tão bem ressaltados por Buss (2000) ao analisar a relação entre promoção de saúde e qualidade de vida. Alguns estudos sociais da surdez demonstram que as dificuldades de comunicação, consequentes do fracasso educacional dos surdos, os colocam em desvantagem no enfrentamento de um imaginário social que os vê como sujeitos pouco dotados intelectualmente. ${ }^{2}$

Buss afirma que"a concepção ampla do processo saúde-doença e de seus determinantes propõe a articulação de saberes técnicos e populares, e a mobilização de recursos institucionais e comunitários, públicos e privados" (Buss, 2000, p.4) para o enfrentamento de problemas de saúde, sobretudo na construção de propostas de intervenção. Considerando a surdez um problema de saúde ainda muito prevalente, a criação de um ambiente favorável à saúde do surdo na família e na escola muda o foco das discussões infindáveis e inúteis sobre métodos de comunicação de sujeitos imaginados para a comunicação de sujeitos reais. Além disso, produz um efeito de deslocamento do olhar sobre a doença para a promoção da saúde e da qualidade de vida desses sujeitos. Acredita-se que para tanto há a necessi-

2 Cf. Borne (2002), para extensa revisão. 
dade de considerar pressupostos teóricos de linguagem e educação que tomem o social como foco do planejamento de intervenções. Dessa forma, o sociointeracionismo na linguagem e na educação assume especial sentido neste trabalho.

\section{Sociointeracionismo: Linguagem e Mediação}

Vygotsky $(1988,1991,1996)$ considera que o adulto (pai-professor), através de uma dialética entre relações inter e intrapsíquicas, promove a passagem de uma zona de aprendizagem proximal para real, desde que seja um bom mediador (Feurstein \& Rynders, 1997). Especificamente em relação à surdez, o autor ressalta a importância da linguagem como aspecto constitutivo do ser social, e não apenas como instrumento de comunicação, e aponta as dificuldades advindas do não partilhamento da mesma língua entre criança surda e professor (Vygotsky, 1991). Na mesma obra, propõe a poliglossia para o desenvolvimento dessas crianças considerando"a mímica ${ }^{3}$ como uma linguagem verdadeira em toda riqueza de sua importância funcional" e que a fala produzida de forma artificial "é somente cópia sem vida da linguagem viva" (p. 190).

Tais constatações são partilhadas em estudos de bilinguismo tanto com surdos como com ouvintes. Eles trazem evidências de que esta experiência, quando precoce, amplia a consciência sobre a linguagem e favorece à criança desenvolver a capacidade de analisar propriedades estruturais da língua (De Hower, 1997; Genesee, 2002), seja ela oral ou de sinais, já que esta é uma língua natural tanto quanto a oral (Brito, 1993; Stokoe, 1960). Para tanto, faz-se necessária a participação de surdos adultos na educação de outros surdos (Goldfeld, 1997), embora estes ainda sofram influência da educação oralista/comportamentalista que receberam (Gesueli, 1998; Quadros, 1997). Baseando-se em Schiff-Myers (2002), que demonstrou que o convívio com pessoas ouvintes, para crianças ouvintes filhas de surdos, entre aproximadamente cinco a dez horas, era o suficiente para que conseguissem adquirir a linguagem oral. Pode-se afirmar algo semelhante para surdos filhos de ouvintes (Bomfim, 2002). O papel do adulto será contribuir para uma conversação na qual a criança será ativa (Lindholm, 1986; De Lemos, 1995; Wood, 1992), e ele deverá estar consciente desse papel de modo a impedir as possíveis rupturas na comunicação do surdo que gerem frustrações em seus pais (Guarinello, 1994). Isso enseja o que Johnson (2001) assinala ao afirmar a necessidade de modificações nas interações iniciais através da teoria da Experiência de Aprendizagem Mediada (EAM), a qual descreve a qualidade da interação entre um aprendiz e uma pessoa chamada de "mediador" (Feuerstein \& Rynders, 1997). O mediador será peça fundamental para o que o autor nomeou de teoria da Modificabilidade Cognitiva Estrutural (MCE), a qual postula que o organismo humano é

3 Mímica: denominação então corrente para a linguagem de sinais. 
dotado de flexibilidade e plasticidade, que o leva a um alto grau de modificabilidade e o faz imprevisível em seu comportamento e desenvolvimento. Tal modificabilidade é um conceito assumido pelo autor tanto diante de sujeitos em desenvolvimento normal e patológico como para aqueles com privação cultural (Feuerstein, 1997; Feuerstein \& Rynders, 1997).

Em relação ao surdo não exposto à língua de sinais precocemente, Brito (1993) constata que pode haver déficits cognitivos, como capacidade de planejamento diante de situações-problema, baixo controle da impulsividade e limitações na adaptação social, o que sugere a limitação linguística como uma privação cultural, indicando a necessidade de que o mediador (falante de LIBRAS ou auxiliado por falante de LIBRAS) observe aspectos propostos por Feurestein (1997). A linguagem terá papel central no processo de mediação (Sasson, 2003), independente da sua modalidade (Feuerstein, 1997, p. 60).

Segundo este autor, existem três categorias de princípios de mediação: os universalmente necessários, os situacionais e os necessários para integrar mudança no funcionamento das estruturas cognitivas (Feuerstein \& Falik, 2001). Esses princípios são agrupados em questões por Sasson (2003) e sintetizados no quadro 1.

Pode-se, observando esses princípios, relacioná-los aos estudos de Wood (1990, 1992), que detectavam que uma das principais dificuldades do ouvinte ao comunicar-se com crianças surdas é o controle excessivo (over control) e que características de comunicação dos professores, as quais facilitam mútuo entendimento e aprendizagem, são essencialmente as mesmas para crianças surdas e ouvintes.

Com tal proposta teórica, buscou-se tornar a escola um espaço de promoção de saúde.

\section{A Escola como Espaço de Promoção da Saúde e de Qualidade de Vida}

Desde a década de 1990, inspiradas por De Lemos (1999), as vertentes interacionista e sócio-histórica, inauguradas no Brasil por um grupo de fonoaudiólogos da PUC de São Paulo (De Vitto, 1994; Freire, 1996) e presentes em outras instituições, sobretudo do Paraná e Santa Catarina, combatem a clínica que adota uma concepção behaviorista de linguagem. Elas demonstram a necessidade de despatologizar a clínica, ou seja, não tomar o sujeito como fruto da sua patologia, mas colocá-la como um limite entre tantos outros que pessoas ditas normais enfrentam. Propõem abandonar a dicotomia saúde vs. doença e tratar com singularidades. Defendem que a escola não é um espaço para a clínica, mesmo quando se está diante de sujeitos que possuem patologia. A escola é um espaço pedagógico no qual o fonoaudiólogo pode ser inserido para discutir questões de linguagem que perpassem as concepções de sujeito, linguagem e aprendizagem (Ber- 
berian, 1995). A proposta no trabalho aqui exposto é de que a escola se torna, quando revê tais concepções, um espaço de promoção de saúde e qualidade de vida.

Buss (2000) realiza extensa revisão do tema "Promoção de saúde e qualidade de vida", destacando o questionamento sobre o papel da medicina e do setor da saúde no enfrentamento do que seriam as causas mais amplas e gerais dos problemas de saúde. $\mathrm{O}$ autor afirma que em países como o Brasil e outros da América Latina, a péssima distribuição de renda, o analfabetismo e o baixo grau de escolaridade são elementos determinantes nas condições de vida e saúde. Focando a questão da escolaridade, fica clara a necessidade de acesso e permanência da criança na escola. Pode-se considerar que, se isso é uma premissa muito importante para sujeitos ditos normais, torna-se ainda mais capital quando se trata de sujeitos com patologias cuja tendência à evasão escolar é maior. No caso da surdez, analisado nesta pesquisa, as barreiras causadas pela comunicação (Brito, 1993; Borne, 2002) podem conduzir a uma interrupção na formação profissional e acarretar péssimas condições de trabalho e inserção social ao surdo. Borne (2002) deixou claro o processo de exclusão social que surdos sofrem quando falham na sua educação e que o não acesso à linguagem é capital para o fracasso na escolarização e no trabalho. Abre-se o caminho para a exclusão social, havendo um processo de menos-valia marcado por uma posição de vítima, que só é minimizada quando o surdo assume sua cultura surda e a Língua Brasileira de Sinais (LIBRAS) como esteios de seu desenvolvimento.

Embora seja importante assumir o caráter universal da promoção da saúde através da transcendência de estudos que abordem indivíduos particulares, sua família ou pequenos grupos, como está caracterizado na segunda revolução epidemiológica (Terris, 1992), quando se trata de um grupo particular como o dos surdos e de uma questão tão delicada como a mudança de concepção pedagógica, são necessárias intervenções iniciais para testar métodos e poder definir políticas que possam ser aplicadas a toda a população de surdos. Como afirma a Carta de Ottawa (WHO, 1986), é importante criar estratégias para forjar ambientes saudáveis por meio do reforço da ação comunitária e do desenvolvimento de habilidades pessoais para a efetiva mediação entre outros interesses sociais e a promoção da saúde. Ainda segundo o documento, tal mediação não é feita apenas por profissionais de saúde, mas por profissionais e grupos sociais ligados a espaços nos quais se insere a pessoa, entre eles a escola. Essa proposição se alinha com a visão de promoção da saúde em Psicologia e Fonoaudiologia exposta por Penteado e Servilha (2004), na qual se indica a necessidade de aproximação das Ciências da Saúde às Ciências Sociais através da fundamentação de seus estudos em pressupostos sociológicos que afirmem a dialética entre sujeito e sociedade, em que o homem é produtor da história de si próprio (Guareschi \& Jovchelovitch, 2000). Elas assumem que o: 
sujeito, suas percepções, representações, os usos que faz de seu corpo e as interpretações sobre sua funcionalidade e seu processo saúde-doença, são constituídos pela sociabilidade num contexto histórico-cultural em que os sujeitos são levados a se ajustar às normas e aos padrões da cultura. (Penteado \& Servilha, 2004, p. 114)

Portanto, pode-se imaginar que, quanto mais naturalística ou "despatologizada" for a situação de contato do surdo com a língua, melhor será seu acesso à cultura, seja do ouvinte ou sua própria.

Em função desta visão é que se pensou uma proposta de intervenção em um grupo de surdos e suas professoras como um piloto para abordar a escola e extrapolar para outras instituições que atendam surdos.

Da Teoria à Práxis: mediando para o professor ser melhor mediador

A pesquisa qualitativa foi efetivada pela filmagem das interações das professoras (uma ouvinte e uma surda) com seus alunos durante um ano letivo. Esses alunos constituíam um grupo de quatro crianças surdas, com perdas auditivas de grau moderado-severo a profundo, na faixa etária de quatro a cinco anos, duas meninas e dois meninos (Aron, Julia, Lia, Rui).

A pesquisa foi realizada em três momentos distintos, sendo que no primeiro foi feita a sondagem da etapa de aquisição de linguagem em que se encontravam as crianças, através da observação de interações espontâneas e da evocação de vocabulário básico focalizado em Bastos (2000) tanto em Português Brasileiro (PB) quanto em LIBRAS. Também foram feitas entrevistas com a Professora ouvinte (PP) e a Professora surda (PL), a filmagem de seis aulas das duas professoras em momentos distintos e, posteriormente, transcrição e análise dessas aulas, a fim de investigar a forma de atuação e a frequência dos princípios interacionistas de Aquisição de Linguagem (AL) e da EAM antes da intervenção.

O método de codificação das transcrições foi baseado em Bernardino (2000), correspondendo: Texto em Maiúscula: expressão em LIBRAS; Texto entre Colchetes: expressão oral; Texto entre Parênteses: descrições contextuais.

A análise da frequência dos princípios da AL e da EAM foi qualificada com a seguinte escala: sempre: considerou que o princípio apareceu com frequência razoável que permitiu identificá-lo como algo ativo constante na interação dos sujeitos; às vezes: em algumas situações esteve ativo na interação e em outras não; esporádico: não ocorreu de forma suficiente para que este princípio pudesse ter funcionalidade na interação.

Após o levantamento de dados do material colhido na primeira etapa do trabalho, foi realizada, durante quatro meses, atividade formadora com as professoras PP e PL através de palestra concernente à Aquisição de Lin- 
guagem com abordagem interacionista e bilíngue, sessões quinzenais da psicóloga com as Professoras PP e PL em momentos distintos para análise e reflexão sobre textos lidos, relativos à teoria de aquisição de linguagem com enfoque interacionista, bem como sobre a EAM e a Modificabilidade Cognitiva Estrutural. Nestes encontros foi feita, ainda, análise de filmagens de quatro sessões de sala de aula com as duas professoras, visando discutir novas estratégias de interação. Este trabalho contou com momentos de crise das professoras e de muita reflexão e conversa a fim de buscar soluções. O pesquisador atuou como o Outro de fora que pôde lançar um olhar crítico e construtivo sobre a atividade de sala de aula.

Na sequência, foram realizadas duas filmagens de sessões, transcrição e análise da pós-intervenção e novas entrevistas com as professoras para verificar se houve ou não evolução no processo de AL pelas crianças, bem como na frequência dos princípios da EAM e da AL com enfoque interacionista nas atividades desenvolvidas em sala de aula. Também foram realizadas entrevistas de acompanhamento com os pais.

Os princípios da EAM observados antes e depois da intervenção foram: Mediação da Intencionalidade e Reciprocidade; Transcendência; Significado; Sentimento de Competência; e da Regulação e do Controle do Comportamento (Sasson, 2003).

E ainda os princípios de aquisição de linguagem com enfoque interacionista foram: se a linguagem surgia como manifestação dialética, inseriase em rotina significativa; se respeitava o campo semântico, se utilizava o brinquedo; se havia exposição natural à língua (sinais ou oral) na rede social individual da criança, promovendo interação dialógica, se desenvolvia motivação subjetiva; e se havia uma língua autorreferenciada, favoreciamse trocas entre todos os envolvidos (Albano, 1999; Bakhtin, 1997; De Hourver, 1997; De Lemos, 1999).

No estudo comparativo para verificar se houve mudanças quanto à AL em PB e em LIBRAS, foi realizada evocação de vocabulário básico, tendo como referência Bastos (2000), e ainda realizou-se a observação de interações espontâneas em sala de aula, as quais foram transcritas segundo o método de codificação Bernardino (2000) e analisadas segundo estágios de aquisição da linguagem propostos por Ramos (2001).

Após intervenção, foi possível identificar evolução significativa na compreensão e expressão tanto da língua oral quanto da língua de sinais, ainda com base em Ramos (2001).Verificou-se que na compreensão da língua oral todas as crianças encontravam-se capazes de compreender frases e na expressão, de produzir palavras. Em LIBRAS, tanto na compreensão quanto na expressão, três crianças atingiram o desenvolvimento narrativo e apenas uma ficou limitada à análise sintática.

Constatou-se que a presença dos princípios fundamentados na teoria interacionista tanto de aprendizagem quanto de $\mathrm{AL}$ e Bilinguismo, 
focalizados no presente estudo, surgiram com frequência importante no pós-intervenção.

Os aspectos voltados aos princípios de $A L$ e bilinguismo foram os que tiveram maior modificação, uma vez que passaram a ocorrer sempre nas situações após intervenção. Quanto aos parâmetros de mediação da aprendizagem, observou-se que estes passaram a ocorrer às vezes e em menos quantidade sempre - tanto nas atividades em LIBRAS quanto em PB -, indício de que houve uma mudança de atitude por parte das professoras quanto à forma de mediar a aprendizagem das crianças. Todos os princípios da EAM propostos foram contemplados em um ou dois aspectos.

Na sequência 1,é possível observar a ordem de atividades desenvolvidas pela Profa. $\mathrm{PL}$, que trabalhou com um grupo de crianças sentadas em semicírculo e tinha como objetivo abordar posições do corpo, verbos relacionados a essas posições e cores primárias, utilizando como material um boneco articulado e potes coloridos. Também se observa na sequência 2 a Profa.PP em atividade na qual explorou, entre outros aspectos, notícias trazidas pelas crianças e objetos de interesse trazidos de casa. $O$ grupo de crianças se encontrava sentado sem semicírculo, com um mural preso à parede, em cuja parte superior estavam escritas em destaque as palavras: QUEM?,TROUXE e O QUÊ?, e, abaixo, espaços para colocar tiras com as palavras e desenhos, duas caixas de sapato encapadas, escrito QUEM?, dentro o nome das crianças e da professora e O QUÊ? (dentro os objetos trazidos pelas crianças). Observa-se em ambos os momentos a ausência de funcionamento linguístico.

Abaixo encontram-se as sequências 1 (Profa.PL) e 2 (Profa. PP) antes da intervenção:

\section{SEQUÊNCIA 1}

120)- Profa. PL.: (Segura boneco articulado, o apoia no peito, aponta o olho do boneco, pega pote azul, aproxima do boneco, aponta ponte de tinta, aponta olho boneco) IGUAL

121) - Profa.PL.: (Aponta pote, aponta olho) AZUL

122) - Aron: (Vai em direção ao boneco, aponta olhos, aponta calção, são ambos azuis)

123) - Profa.PL.: (Olha) AZUL

124) - Profa.PL.: (Aponta calção)

125) - Aron: (Aponta o pé, que é azul)

126) - Profa. PL.: (Aponta pé boneco) AZUL 


\section{SEQUÊNCIA 2}

5) - Profa.PP: [O que é isso?] (Mostrando objeto).

6) - Aron: EU

7) - Ana: MAÇÃ (Articula o /mãã/)

8) - Aron: EU MAÇÃ (Articula) MAÇÃ, MAÇÃ

9) - Profa.PP: [Uma maçã, maçã, am, am, am]

10) - Profa. PP: [É para brincar assim?] (Rola maçã no chão) [é] (Afirma com cabeça)

11) - Aron: NÃO (Articula /ão/)

12) - Profa.PP: [Não, é para comer] (Simultaneamente) [am, am, am]

13) - Aron:NÃO (Com o dedo) COMER

É possível observar a evolução nas atividades desenvolvidas após intervenção com a Profa.PL na sequência 3, cuja intenção era introduzir uma história e estabelecer relação entre os personagens da história e situações de vida das crianças. O material utilizado foi o livro colorido e ilustrado da história "O Gato Agricultor" (alguns bichos de pelúcia e objetos presentes na história). Na sequência 4, vê-se a Professora PP introduzir, através do brincar, conceitos relacionados aos animais selvagens com miniaturas de animais para o campo temático do zoológico. A atividade teve três momentos distintos: introdução à atividade; construção do zoológico; e, após isto, foram introduzidos bonecos em miniatura (mãe, pai, bebê, menino, menina e vovó) visitando o zoológico.

Abaixo as sequências 3 (Profa. PL) e 4 (Profa.PP) após intervenção:

\section{SEQUÊNCIA 3}

256) - Profa. PL. para Aron: VOCÊ VIU, GATO DORMINDO, ACORDOU, SE ARRUMOU, FOI ANDANDO, ANDANDO, VIU VACA. PEGOU BALDE, COLOCOU, TIROU LEITE, TIROU LEITE. PEGOU BALDE, LEVOU, PÔS LEITE COPO, BEBEU LEITE. VOCÊ GOSTA DE LEITE, BEBER? (Enquanto isso, Aron e Lia prestam atenção na Profa. e Júlia olha um livro.) 
257) - Aron para Profa. PL.: SIM (com a cabeça).

258) - Profa.PL.para Lia:VOCÊ GOSTA BEBER LEITE GOSTA, CASA LÁ. LEITE BEBER?

259) - Lia: SIM (com a cabeça).

260) - Aron para Profa. PL.:TIRAR LEITE, VACA EU CASA TEM.

261) - Profa. PL.:VOCÊ CASA. VOCÊ PÕE NO COPO, MEXE,TOMA LEITE?

262) - Aron: SIM (com a cabeça).

263) - Profa. PL. para Júlia:VOCÊ, LEITE CASA BEBE LEITE?

264) - Júlia: (Olha Profa. PL.) SIM (com a cabeça).

265) - Profa. PL.:VOCÊS TRÊS, SIM...

\section{SEQUÊNCIA 4}

73) - Lia: (Entrega outro animal para Profa.)

74) - Profa. PP.: [E esse aqui o que é?]

75) - Lia: LEÃO.

76) - Profa. PP.: [O que é isso aqui?]

77) - Júlia: LOBO, (Emite) /obo/.

78) - Prof.PP.: [O lobo, lobo]

79) - Aron para Júlia: CACHORRO? (Pega o lobo da mão da Profa., olha. Mostra para Profa.) CACHORRO?

80) - Profa.PP.: NÃO [Não].

81) - Aron:LOBO (Articula). 
Em relação à percepção das mães sobre as evoluções de seus filhos, é possível observar que elas passaram a acreditar mais neles. Nas situações de casa no início do ano, as crianças não faziam perguntas, não demonstravam interesse pelas coisas que ocorriam à sua volta, limitando-se a pedir o que estava à vista, o que indica tendência a fixar-se no concreto e em dados observáveis. Outro aspecto refere-se à atitude de isolar-se. A mudança é percebida em todos os relatos das mães:

MAron - "Antes ficava só olhando, não participava, não sabia fazer perguntas."

MJulia - "difícil ela fazer pergunta, no início do ano ela mostrava coisas que tinha feito. Mas conversa, pergunta, assim, não. Se eu estava fechando a porta, a janela, ela perguntava se estava chovendo, ela sabia o sinal de chuva, só isso ela perguntava, era a única coisa que perguntava.... antes ficava só olhando, agora, não.... os outros não entendiam e ela acabava ficando sozinha. Ela pedia quando via as coisas, depois ela esquecia."

MLia - "não perguntava, só olhava, ficava assim com aquela cara de que não estava entendendo. Só pedia quando estava perto de algo que ela queria, mostrava, apontava."

MRui -“Não fazia perguntas, ...só pedia coisas que estavam presentes na situação, se isolava, não tentava participar."

Ao final do ano as mães relataram que todas as crianças participavam do que acontecia em casa, faziam perguntas, pediam coisas tanto próximas como ausentes. Queriam saber o que ocorria em torno delas. Duas mães observaram que ficaram surpresas diante da evolução de suas crianças, percebendo que agora entendem o que se passa à sua volta, fazem perguntas, contam o que viram, querem saber o nome e o sinal, falam o nome de pessoas que aprenderam. Todas as mães consideram que atualmente as crianças brincam melhor, se fazem entender e relatam uma diminuição importante nas crises de birra que eram frequentes antes da intervenção.

Outro resultado importante foi o efeito multiplicador do trabalho com as duas professoras sobre as demais professoras da escola. $\mathrm{O}$ grupo percebeu a maior evolução do grupo de crianças participantes desta pesquisa em comparação a todos os demais grupos que têm passado pelo mesmo nível de escolaridade. Há relatos de que crianças em níveis mais avançados de escolarização não estão com o domínio linguístico dos sujeitos desta pesquisa. As professoras foram solicitadas pelas colegas a passar 
sua experiência adiante. A primeira pesquisadora segue até hoje fazendo esta formação na escola.

Os resultados permitem observar que no pré-intervenção a abordagem de linguagem caracterizava um modelo comportamentalista, no qual as crianças eram tratadas como receptoras passivas da informação, mesmo na língua de sinais, possivelmente em função de a professora surda ter sido alvo de educação igualmente comportamentalista (Gesueli, 1998; Quadros, 1997). O uso do vocabulário era restrito e oferecido na forma de perguntas na estrutura mural com caixas de interrogação (chave de Fitzgerald) (Lindholm, 1986). No entanto, muitas vezes as respostas eram dadas pelas professoras após a enunciação da pergunta, não havendo tempo para o processo de elaboração mental que pudesse desencadear a necessidade para apreender (Feuerstein, 1997; Sasson, 2003). Assim, pode-se dizer que a concepção de aprendizagem também era comportamentalista (Goldefeld, 1997; Skinner, 1978; Trenche, 1995), pois a forma de explorar os elementos apresentados ocorria em uma sequência fixa, o que sugere tendência de base estruturalista, que não considera a heterogeneidade da língua (De Lemos, 1999) nem o processo interlocutivo (De Lemos, 1995). As contribuições das crianças não eram levadas em conta, uma vez que a confirmação de tentativas de emissão delas não eram mediadas para ensejar o sentimento de competência, de modo a sentir suas experiências como valorizadas e diferenciadas, como propõe Feurstein (1997).

Quanto às concepções de aquisição de linguagem, ocorreu um diálogo de tipo instrucional (Trenche, 1995; Vygotsky, 1991), o qual se caracterizou pela introdução direta sobre diferentes aspectos da linguagem. As professoras utilizaram informação filtrada, segundo critério de complexidade da língua, com a finalidade de "ensinar a falar" em etapas "adequadas" ao desenvolvimento da criança, acreditando que tais estratégias facilitariam a aquisição de linguagem. Essa visão criou pseudointerações, visto que a professora introduzia e desenvolvia os turnos da conversação (Souza, 1998; Trenche, 1995).

Outro aspecto importante foi o fato de não ter havido preocupação em contextualizar a situação e favorecer o desenvolvimento de uma relação dialógica, pois a professora introduzia e desenvolvia os turnos de conversação (Souza, 1998; Trenche, 1995).

Nas sequências 2 e 4, no pós-intervenção, observou-se uma nova ideia quanto à forma como se adquire a linguagem, visto que as Profas. PL e PP desenvolveram conversação com as crianças sobre os elementos apresentados, e o vocabulário surgiu a partir de situações contextualizadas.

Não se observou preocupação em "filtrar a linguagem", a qual foi colocada no processo discursivo, evitando assim situação de controle e possibilitando o surgimento de estrutura frasal (turno 260), o que indica explosão de vocabulário e indício do uso de pronomes para"referente não presente" (Quadros, 1997), confirmando o observado em Góes (1999) de 
que aspectos como inflexibilidade conceitual-semântica e restrição de vocabulário não são intrínsecos à surdez.

Observou-se, ainda, que as professoras utilizaram-se de diferentes estruturas frasais para questionar e estabelecer relação dialógica, o que possibilitou o acesso a uma língua estruturada e remeteu os alunos a situações passadas (Goldfeld, 1997; Johnson, 2001).

No pós-intervenção, as professoras interagiram levando em consideração as contribuições das crianças, referendando suas descobertas, o que indica mediação do sentimento de competência ao designar significados para as realizações competentes das crianças, conduzindo-as a estabelecer interação dialógica (Sasson, 2001), em que tiveram participação ativa, tornando-se responsivas às solicitações das professoras (Wood, 1992). Com isso, as crianças deram indícios da fase denominada análise sintática complexa, prevista tanto em língua oral (Ramos, 2001) como nas primeiras combinações de sinais (Quadros, 1997).

As Profas. PL e PP atribuíram valor às respostas das crianças e criaram situações para que ocorresse a continuidade de conversação, possibilitando um processo interativo que as levou a responder, favorecendo que levantassem hipóteses (Bakhtin, 1997). Isso sugere que a interação dialógica pode garantir à criança surda, em processo inicial de $A L$, uma interação verdadeira tanto na modalidade gestual quanto na modalidade oral (De Lemos, 1995; Vygotsky, 1995; Wood, 1992).

Na sequência 4, uma das crianças introduziu um novo elemento à situação (turno 74), o que desencadeou uma sequência de interações dialógicas, nas quais a Profa.PP mediou a busca de significados ao questionar o que era o elemento apresentado por Lia, diante da resposta errada da criança, a qual não rejeitou, procurou confirmação através de uma atitude de dúvida. Isso desencadeou a necessidade de levantar hipóteses, ao que (turno 77) uma das crianças respondeu corretamente. A professora confirmou a resposta, ou seja, mediou o sentimento de competência (Sasson, 2003). Imediatamente uma terceira criança interveio (turno 79) e interagiu com a colega, e formulou uma pergunta sobre sua dúvida, e, em seguida, dirigiu-se à Profa. PP para confirmar sua hipótese. A professora disse que a resposta dela não estava correta, o que a levou a aceitar a resposta do colega. Portanto, nesta sequência, pode-se identificar a mediação para o significado e para a ampliação do sentimento de competência (Sasson, 2001).

Pode-se perceber uma cadeia de textos discursivos nos quais o enunciado da criança foi ouvido e ressignificado (De Lemos, 1995) e observouse, ainda, que a língua passou a ser objeto de reflexão (Ramos, 2001). Como era esperado, as crianças evoluíram mais em LIBRAS do que em português, mesmo esta língua estando com maior frequência na rotina acadêmica das crianças (mais aulas em PB). Sabe-se que, em intervalos de recreio, as crianças tinham acesso maior a LIBRAS pela presença de surdos nos serviços da escola e também pela presença de colegas surdos de todas as idades. Isso 
comprova que, por mais que o adulto tente exercer um supercontrole da língua, o ambiente de imersão naturalístico é o melhor para a aquisição da linguagem (De Hourver, 1997; Ramos, 2001).

Ambos os profissionais demonstraram, em sua prática, uma nova forma de interação que promoveu no grupo de crianças alto grau de reciprocidade, aumento da busca de significado, ampliação do sentimento de competência e possibilidade de transcender à situação presente. Isso sugere que essas crianças passaram a ter acesso a formas abstratas de pensamento, ou seja, houve ampliação do funcionamento cognitivo e emocional, o que possibilitou domínio de conceitos e capacidade em interpretar os estímulos do meio, comparando-os e organizando-os, sendo este um aspecto necessário à solução de tarefas (Feuerstein \& Rynders, 1997; Feuerstein \& Falik, 2001; Goldfeld, 1997; Sasson, 2003).

Os princípios de mediação mais frequentes foram os da Intencionalidade e Reciprocidade, do Sentimento de Competência e de Significado, e os menos frequentes foram Mediação da Transcendência e da Regulação para o Controle do Comportamento. Portanto, houve uma modificação intensa na forma de pensar, sentir e agir das professoras a partir da visualização de seu trabalho e do conhecimento de abordagens mais abrangentes de aprendizagem e linguagem. Tal mudança atingiu os outros professores da escola, no início com resistência a implementar a nova abordagem. Isso demonstra como a intervenção bem-sucedida com um grupo-piloto é importante para o efeito multiplicador desejado. Acredita-se que, se houvesse uma imposição do método novo, os resultados não seriam os mesmos. Há necessidade de formação continuada e debate com o professor para que possa ser convencido a mudar sua práxis (Sasson, 2003).

Uma questão que surge é: o que ocasionaria a intensa utilização da abordagem comportamentalista tão frequente tanto para a aprendizagem quanto para a linguagem no ensino de crianças surdas? Este trabalho, no contato com as professoras, sugere algumas respostas.

Em primeiro lugar, o desconhecimento da abordagem interacionista é ausente na formação profissional das professoras e, talvez de modo mais importante, ausente na sua formação pessoal. A escola, em geral, ainda é muito comportamentalista, tratando o sujeito (ouvinte, surdo) como um memorizador de conteúdos cujo reforço positivo será uma nota alta. Percebe-se nas entrevistas iniciais com as professoras que este foi seu histórico, sobretudo para a Profa.PL., que, por ser surda, esteve exposta a práticas comportamentalistas mais marcadas ${ }^{4}$ e apresentou maior dificuldade inicial em mudar sua prática.

Outro ingrediente favorecedor de tais práticas parece ser a necessidade de manter o controle da situação, sobretudo quando há uma diferença linguística. Percebe-se isso de modo intenso no ouvinte diante do surdo. Ele teme que o surdo comunique em sinais algo que ele não possa enten-

4 Cf. a história da surdez em Curitiba (Borne, 2002). 
der. O reverso desta situação é o surdo que teme conviver em comunidades ouvintes. Tal posição também é possível em situações de bilinguismo em ouvintes. Assim, o que parece uma discussão tão particular na educação do surdo está descrito em vários autores como situações inerentes ao bilinguismo (De Hourver, 1997; Genesee, 2002).

Outras respostas podem ser hipotetizadas, como a presença de uma representação social da surdez tanto para surdos quanto ouvintes como uma desvalia, conforme assinala o trabalho de Borne (2002). A descrença na potencialidade do surdo é enorme em toda a história desses sujeitos. Nesta perspectiva, pode-se levantar a hipótese de que o fato de se estar diante de uma patologia tira a naturalidade das situações e pode estar induzindo a tratar como desvalia o que é apenas uma diferença, e tornar a sala de aula um arremedo de uma sessão terapêutica mal conduzida.

Em relação à crença nas potencialidades do surdo, é importante analisar o depoimento das mães sobre a evolução de seus filhos. Tais depoimentos demonstram como o trabalho escolar bem-feito foi suficiente para mudar o funcionamento linguístico das crianças e como as mães acompanharam e fizeram parte dessa mudança. Cabe ressaltar que as mães da escola participam de grupos de pais com a primeira autora da pesquisa e outros especialistas da escola. A percepção do filho como alguém competente (Feuerstein \& Rynders, 1997; Feuerstein \& Falik, 2001; Sasson, 2003) permite pensar os efeitos disso no relacionamento familiar. O convívio tornou-se mais fluido, com participação constante da criança na conversação familiar. Ela passou a ser ouvida, percebida em suas necessidades, em sua forma de ser. Não há dúvida de que essa mudança é um aspecto relevante na construção de saúde mental das crianças. Borne (2002) é precisa ao descrever o relato de surdos cuja educação mal-sucedida gerou problemática pessoal e social importante. Em todos os relatos descritos pela autora fica clara a falha comunicativa como cerne do sucesso ou insucesso dos seus entrevistados.

Assim, a intervenção produzida nesta pesquisa pode ser afirmada como um espaço de promoção de saúde e qualidade de vida, já que houve uma melhora significativa na comunicação dos sujeitos em seu domínio linguístico e uma mudança teórica e prática nas professoras-alvo da pesquisa.Tal mudança se refletiu em outras turmas atendidas pelas professoras e teve efeito disseminador na escola. Isso sugere que novos métodos pedagógicos impostos por regras governamentais ou por diretrizes de saúde não saem do papel se não houver uma formação continuada na escola, e o profissional a saúde pode participar dela como promotor de saúde se buscar subsídios filosóficos, sociológicos e pedagógicos para seu trabalho conforme assinalam Penteado e Servilha (2004). O sucesso na intervenção fonoaudiológica escolar pode ter como consequência a permanência da criança na escola, aspecto crucial para a promoção de saúde e qualidade de vida, considerando os conceitos revisados por Buss (2000). Também faz 
pensar que a escola não é um espaço para a clínica, mas um espaço de participação do fonoaudiólogo (Berberian, 1995) e do psicólogo na discussão pedagógica e na formação do professor. Como especialistas de linguagem e cognição, eles podem ser parceiros na construção de uma nova forma de conceber e praticar a comunicação, uma nova forma de ser.

\title{
Considerações Finais
}

A experiência realizada na escola permitiu constatar na práxis que a teoria sociointeracionista de base vygostiana e a teoria interacionista de aquisição da linguagem de Cláudia de Lemos foram fios condutores importantes da reflexão realizada entre as pesquisadoras e as professoras, pois promoveram mudanças importantes que se estenderam ao ambiente familiar.

Outro aspecto importante a ressaltar foi o efeito multiplicador da intervenção nos demais profissionais, demonstrando que a proposta foi efetiva como iniciadora de um processo de mudança pedagógica, sobretudo nos processos linguísticos e de mediação, em toda a escola.

\section{Deafness, Mediation and Language in the School}

\begin{abstract}
This study examines how the principles of mediation, based in the Mediated Learning Experience (MLE), by Reuven Feuerstein, and the Language Acquisition in an interactionist approach, may interfere with the educational and/or therapeutic practices in deafness, considering the language with focus of learning/acquisition. The research context was four deaf children and their two teachers, also including a deaf speaker of LIBRAS (Brazilian Sign Language) and another listener responsible for the Portuguese. The objective was to examine how frequently were the principles of mediation and purchase before and after an intervention training with the teachers. It was also investigated the consequences in the language of children in both languages and in familiar context. The results shown significant consequences in the communication of children, followed by mothers in the family and changes in the mediation process of teachers in the classroom. Among the most frequently found one of the intent-reciprocity, search for meaning, transcendence and mediation of a feeling of competence. Children have become more active, both in the classroom and in the family.
\end{abstract}

Keywords: Mediation. Learning. Language. Interaction. Deafness. 


\section{Surdité, Médiation et Langue dans l'École}

Résumé: Cette étude examine comment les principes de la médiation,en se fondant sur l'Expérience de l'Apprentissage Mediatisé (EAM), de Reuven Feuerstein, et l'acquisition de la langue dans un abordage interactioniste, peuvent interférer avec les pratiques éducatives et/ou thérapeutiques dans la surdité, compte tenu de la langue avec l'orientation de l'apprentissage /acquisition. La recherche fait partie d'un groupe de quatre enfants sourds et deux enseignants, un parlant de sourds LIBRAS (Langue Brésilienne des Signes) et un autre auditeur responsable du portugais. L'objectif était d'examiner comment ont été souvent les principes de la médiation et l'achat avant et après une intervention de formation avec les enseignants. Il a également examiné les conséquences dans la langue des enfants dans les deux langues et dans la famille. Les résultats ont montré d'importantes conséquences dans la communication des enfants, suivis par les mères dans la famille et les changements dans le processus de médiation des enseignants en classe. Parmi les plus fréquemment on a trouvé ceux d'intention de la réciprocité, recherche de sens, la transcendance et la médiation d'un sentiment de compétence. Les enfants sont devenus plus actifs, à la fois en classe et dans la famille.

Mots clés: Médiation. Apprentissage. Langue. Interaction. Surdité.

\section{Sordera, Mediación y Lenguaje en la Escuela}

Resumén: Esta investigación analiza los principios di mediación y su interferencia en las praxis educacionales, con bases en la experiencia del aprendizaje mediado, de Reuven Feuerstein y del abordaje interaccionista de la adquisición del lenguaje. El contexto de la investigación ha sido un grupo de cuatro niños sordos y sus maestras, una de LIBRAS (lengua brasilera de señales) y otra, oyente hablante de portugués. El objetivo además el análisis de la frecuencia de los principios de la mediación y de la adquisición del lenguaje antes y después de la intervención formativa de las maestras. También se ha investigado los resultados en el lenguaje de los niños en las dos lenguas y en el contexto familiar. Los resultados han demostrado consecuencias importantes en el lenguaje de los niños observadas por sus madres en el contexto familiar y cambios en el proceso de mediación de las maestras en la clase antes y después de una intervención formativa con las maestras. Entre los principios más frecuentes estuvieron intencionalidad-reciprocidad, búsqueda del significado, transcendencia y mediación del sentimiento de la habilidad. Los niños se volvieran más activos, en la clase y en el contexto familiar.

Palabras clave: Mediación. Aprendizaje. Lenguaje. Interacción. Sordera. 


\section{Referências}

Albano, E. C. (1999). Da fala à linguagem... Tocando de ouvido. São Paulo: Martins Fontes.

Bakhtin, M. (1997). Marxismo e filosofia da linguagem (8a ed., M. Lahual \& Y. Frateschi Vieira, trads.). São Paulo: HUCITEC.

Bastos, J. C. (2000). Vocabulário básico em um grupo de crianças na faixa etária de 1 ano a 2 anos e 6 meses do Balneário Camboriú e Itajaí: Discussão da Metodologia de Coleta. Dissertação de Mestrado, Faculdade de Ciências Biológicas e da Saúde, Universidade Tuiuti do Paraná, Curitiba, PR.

Bernardino, E. L. (2000). Absurdo ou lógica? A produção lingüística do surdo. Belo Horizonte: Profetizando Vida.

Berberian, A. P. (1995). Fonoaudiologia e educação: um encontro histórico. São Paulo: Plexus.

Bomfim, R. O. (2002). Concepções de linguagem e educação e a defesa da experiência de aprendizagem mediada como parâmetro de interação entre um grupo de crianças surdas e suas professoras. Dissertação de Mestrado, Faculdade de Ciências Biológicas, Universidade Tuiuti do Paraná, Curitiba, PR.

Borne, R. (2002). Representações sociais da surdez. Dissertação de Mestrado, Universidade Tuiuti do Paraná, Curitiba, PR

Brito, L. F. (1993). Integração social e educação de surdos. Rio de Janeiro: Babel.

Buss, P. M. (2000). Promoção da saúde e qualidade de vida. Ciência \& Saúde Coletiva, 5(1), 163-177.

De Hourver, A. (1997). Aquisição bilíngüe da linguagem. In P. E. Fletcher \& B. M. Whinney, Compêndio de linguagem da criança (M. A. G. Domingues, trad., pp. 185208). Porto Alegre: Artes Médicas.

De Lemos, C. T. G. (1995). Língua e discurso na teorização sobre aquisição da linguagem. Porto Alegre: Letras de Hoje.

De Lemos, C. T. G. (1999). A criança com(o) ponto de interrogação. In R. R. Lamprecht, Aquisição de linguagem: questões e análises (pp. 39-50). Porto Alegre: EDPUCRS.

Feuerstein, R. (1997). Teoria de la modificabilidad cognitiva estrutural. In R. Feuerstein, Es modificable la inteligencia? (pp. 11-23). Madrid: Bruño. 
Feuerstein, R., \& Rynders, J. E. (1997). Don't accept me as I am: Helping "retarded" people to excel (2a ed.). Renewed: Sky Light Training.

Feuerstein, R., \& Falik, L. H. (2001). Cognitive modificability: A needed perspective on learning for the 21 st century. Recuperado em 28 de julho de 2001, de http://www. icelp.org/previewsofpapers/cogmolfiabltyprspctv.html

Genesee, F. (2002). Desenvolvimento da linguagem bilíngüe em crianças préescolares. In D. Bishop \& K. Mogford, Desenvolvimento da linguagem em circunstâncias excepcionais (M. Patrão Lomba \& L. Lankszner, trads., pp. 73-98). Rio de Janeiro: REVINTER.

Gesueli, Z. M. (1998). A criança surda e o conhecimento construído na interlocução em língua de sinais. Tese de Doutorado, Faculdade de Educação, Universidade Estadual de Campinas, Campinas, SP.

Góes, M. C. R. (1999). Linguagem, surdez e educação (2a ed.). Campinas, SP: Autores Associados.

Goldfeld, M. (1997). A criança surda: linguagem e cognição numa perspectiva sóciointeracionista. São Paulo: Plexus.

Guareschi, P., \& Jovchelovitch, S. (Orgs). (2000). Textos em representações sociais (6a ed.). Petrópolis, RJ: Vozes.

Guarinello, M. C. (1994). Bilinguismo para crianças surdas pequenas. Dissertação de Mestrado, Departamento de Educação, Universidade de Bristol.

Johnson, M. J. (2001). Mediational strategies for deaf students: Implementing Feuerstein's instrumental enrichment to address cognitive deficits. Recuperado em 23 de setembro de 2001, de http://www.umnitoba.ca/unervoc/conference/ papers/jhnson.pdf

Lindholm, K. J. (1986). El desarrollo de la comunicación en el español de niño bilingues (españhol/ingles): La influencia de la comunicación de los padres. In Aquisición de lenguaje (pp. 68-91). Frankfurt: Vervuert.

Penteado, R. Z., \& Servilha, E. A. M. (2004). Fonoaudiologia em saúde pública/coletiva: compreendendo prevenção e o paradigma da promoção da saúde. Revista Distúrbios da Comunicação, 16(1), 107-116.

Quadros, R. M. (1997). Educação de surdos: a aquisição da linguagem. Porto Alegre: Artes Médicas. 
Ramos, A. P. (2001). A aquisição da linguagem oral: fases e implicações educacionais. In E. D. Roman \& V. Steyer, A criança de 0 a 6 anos na educação infantil: um retrato multifacetado (pp. 78-87). Canoas, RS: Ed. ULBRA.

Sasson, D. (2001). Del cambio estructural a la autoimagen positiva. In R. Feuerstein, Es modificable la inteligencia? (pp. 177-194). Madrid: Bruño.

Sasson, D. (2003). Del cambio estructural a la autoimagem positiva. Recuperado em 18 de julho de 2003, de file:// A:Del\%20cambio\%20estructural\%20a\%201a\%20 autoimagem\%20positiva\%20-\%20Articulos\%20S_E_A_M_\%20-\%20P_E

Schiff-Myers, N. (2002). Crianças dotadas de audição, filhas de pais surdos. In Desenvolvimento de linguagem em circunstâncias excepcionais (M. Patrao Lomba \& L. Lankszner, trads., pp. 51-72). Rio de Janeiro: REVINTER.

Skinner, F. B. (1978). O comportamento verbal. São Paulo: Cultrix.

Souza, R. M. (1998). Que palavra que te falta? In Linguística e educação: considerações epistemológicas a partir da surdez. São Paulo: Martins Fontes.

Stokoe, W. C. (1960). Sign language structure: An outline of the visual comunication systems of the american deaf (2a ed.). Silver Springs, Maryland: Lainstok.

Terris, M. (1992). Conceptos de la promoción de la salud: dualidades de la teoria de la salud publica. In: OPAS 1996. Promoção de la Salude: uma antologia (pp. 37-44). Washington, DC: OPAS.

Trenche, M. C. B. (1995). A criança surda e a linguagem no contexto escolar. Tese de Doutorado, Pontifícia Universidade Católica de São Paulo, São Paulo, SP.

Vygotsky, L. S., \& Luria, A. R. (1988). Linguagem, desenvolvimento e aprendizagem (2a ed., M. da P. Villalobos, trad.). São Paulo: Ícone.

Vygotsky, L. S. (1991). Pensamento e linguagem (3a ed., J. L. Camargo, trad.). São Paulo: Martins Fontes.

Vygotsky, L. S. (1995). Fundamentos de defectologia (L. M. Del C. Parce Fernandez, trad.). Madrid: Pueblo y Educación.

Vygotsky, L. S. (1996). A formação social da mente: o desenvolvimento dos processos psicológicos superiores (5a ed., J. Cipolla Neto, L. S. Merma Barreto \& S. C. Afache, trads.). São Paulo: Martins Fontes. 
WHO. (1986). Carta de Ottawa. In Promoção da saúde: Cartas de Ottawa, Adelaide, Sundaswall e Santa Fé de Gogotá (pp. 11-18). Brasília, DF: Ministério da Saúde.

Wood. D. (1990). Cognição e aprendizagem. Trabalho apresentado no Congresso Internacional de Educação de Surdos. Nova York.

Wood. D. (1992). Teaching and talking with deaf children (3th ed.). Great Britain: John Willey \& Sons.

Rute Oliveira do Bomfim, Psicóloga, Mestre em Distúrbios da Comunicação pela Universidade Tuiuti do Paraná. Rua Eng. Arthur Bettes, 215, ap. 203. CEP: 80610-290, Curitiba, PR. Endereço eletrônico: ruobom@yahoo.com.br

Ana Paula Ramos de Souza, Doutora em Letras, docente do Programa de Distúrbios da Comunicação Humana da Universidade Federal de Santa Maria. Rua Raposo Tavares, 134 apto.401.CEP: 97560-015, Santa Maria, RS. Endereço eletrônico: ramos1964@uol. com.br

Recebido em: 30/11/2008

Aceito em: 31/07/2009 
